두 I픈 소

Jurnal Gentiaras Manajemen dan Akuntasi

Laman Jurnal: jurnal.gentiaras.ac.id/index.php/Gema/index

ISSN : 2086-9592 (p) , 2721-5490 (e)

\title{
Pengaruh Kualitas Produk dan Kualitas Pelayanan Terhadap Kepuasan Konsumen di Kedai Kaizar Lahat
}

\author{
Hayani Hayani \\ Sekolah Tinggi Ilmu Ekonomi Serelo Lahat, Sumatera Selatan \\ *email: Hayanirolani1010@gmail.com
}

\begin{tabular}{|c|c|}
\hline$A R T I C L E \quad I N F O$ & $A B S T R A C T$ \\
\hline $\begin{array}{l}\text { Artikel History: } \\
\text { Received: May 25, } 2021 \\
\text { Revised: July 29, } 2021 \\
\text { Published: July 31, } 2021\end{array}$ & $\begin{array}{l}\text { This study aims to determine: (1) the effect of product quality on customer } \\
\text { satisfaction of Kedai Kaizar Lahat (2) the quality of service on customer satisfaction } \\
\text { of Kedai Kaizar Lahat, and (3) the effect of product quality and service quality on } \\
\text { customer satisfaction of Kedai Kaizar Lahat. This research is a survey research with } \\
\text { an associative design. The population in this study were all consumers of Kedai } \\
\text { Kaizar Lahat. The sample of this research is most consumers of Kedai Kaizar Lahat } \\
\text { in Kab. Lahat, amounting to } 60 \text { people. Data collection using a questionnaire that } \\
\text { has been tested for validity and reliability. The data analysis technique used in this } \\
\text { study is multiple regression analysis. The results of the study with a significance } \\
\text { level of 5\% found that (1) product quality has a positive effect on customer } \\
\text { satisfaction, (2) service quality has a positive effect on customer satisfaction and (3) } \\
\text { product quality and service quality have a positive and significant effect on customer } \\
\text { satisfaction. }\end{array}$ \\
\hline
\end{tabular}

\section{N F O A R T I K E L}

\section{Riwayat Artikel:}

Diterima: 25 Mei 2021

Direvisi:29 Juli 2021

Dipublikasikan: 31 Juli 2021

Kata kunci:
Kualitas Produk dan Pelayanan,
Kepuasan Konsumen.

\section{A B S T R A K}

Penelitian ini bertujuan untuk mengetahui: (1) pengaruh kualitas produk terhadap kepuasan konsumen Kedai Kaizar Lahat (2) kualitas pelayanan terhadap kepuasan konsumen Kedai Kaizar Lahat, dan (3) pengaruh kualitas produk dan kualitas pelayanan terhadap kepuasan konsumen Kedai Kaizar Lahat. Penelitian ini merupakan penelitian survey dengan rancangan asosiatif. Populasi dalam penelitian ini adalah seluruh konsumen Kedai Kaizar Lahat. Sampel penelitian ini adalahsebagian konsumen Kedai Kaizar Lahat di Kab. Lahat yang berjumlah 60 orang. Pengumpulan data menggunakan kuesioner yang telah diuji validitas dan reliabilitasnya. Teknik analisis data yang digunakan dalam penelitian ini adalah analisis regresi berganda. Hasil penelitian dengan taraf signifikansi 5\% menemukan bahwa(1) kualitas produk berpengaruh positif terhadap kepuasan konsumen, (2) kualitas pelayanan berpengaruh positif terhadap kepuasan konsumen dan (3) kualitas produk dan kualitas pelayanan berpengaruh positif dan signifikan terhadap kepuasan konsumen. 


\section{PENDAHULUAN}

Pada dasarnya manusia memiliki dua kebutuhan yang harus dipenuhi, yaitu kebutuhan fisik dan rohani. Salah satu kebutuhan fisik yang penting untuk dipenuhi adalah kebutuhan akan makanan. Makanan sebagai kebutuhan primer dan mendasar bagi setiap manusia menempati porsi yang cukup besar dari total pengeluaran konsumsi individu. Hal ini menunjukan bahwa bisnis dalam bidang makanan dan jasa boga di Indonesia cukup menjanjikan.

Pemenuhan kebutuhan dan keinginan sangat ditentukan oleh tingkat kepentingan maupun kepuasan pelanggan itu sendiri. Seiring makin banyaknya aktivitas diluar rumah yang sangat bervariasi oleh manusia, maka kesempatan orang yang bersifat cepat, praktis dan nyaman semakin tinggi. Jumlah penduduk yang sangat besar membawa dampak penting bagi kehidupan masyarakat Indonesia.Salah satu dampak penting adalah pemenuhan kebutuhan pangan yang sangat banyak untuk memenuhi konsumsi penduduk. Hal ini membawa dampak positif bagi para pengusaha untuk melihat peluang bisinis dan mempengaruhi pelanggan Indonesia yang bersifat konsumtif.

Kabupaten Lahat mempunyai banyak objek wisata ini menjadi salah satu pendukung bagi pengusaha untuk membuka usahanya di Kabupaten Lahat. Bisnis yang berkembang di kota ini sangat beragam, mulai dari bisnis makanan (kuliner), pakaian (konveksi), kerajinan hingga bisnis perbankan. Dengan beragamnya bisnis tersebut tentu membawa dampak pada persaingan bisnis. Bisnis yang berkembang sangat pesat adalah bisnis makanan atau dikenal dengan istilah kuliner. Semakin maraknya ragam kuliner yang disajikan dan berkembangnya jumlah gerai yang menyajikan kuliner tersebut, menjadi daya tarik untuk meneliti tentang bisnis kuliner yang difokuskan pada salah satu tempat kuliner yaitu restoran

Kedai Kaizar Lahat adalah sebuah industri yang bergerak dalam bidang kuliner restoran. Lokasi tidak jauh dengan kota Lahat dan mudah dijangkau. Kedai kaizar berada di Jalan lingkar lahat, simpang empat lampu merah kodim samping Gor lahat. Kedai kaizar lahat berupaya menyajikan menu-menu yang sesuai dengan karakteristik konsumen baik dari segi rasa, macam/jenis, penampilan, porsi maupun harga. Berbagai macam hidangan makanan dengan menu unggulan Aneka masakan rumahan seperti pindang salai, Terong hehancang, paketan nasi kebuli, nasi samin danlain - lainnya. Menu lain yang tak kalah menggoda adalah ayam goreng kampung masak nanas, Pindang patin dan Aneka sayuran seperti cah kangkung, karedok, sayur asem, cap cay. Beberapa pilihan sambal dan minuman segar yang menjadi pelengkap hidangan. 
Setelah melakukan observasi langsung ke Kedai Kaizar Lahat, mendapati kedai ini selalu ramai di siang hari terutama saat jam makan siang. Tentunya banyaknya konsumen ini mewakili banyaknya kesan dan testimoni yang timbul dengan kepuasan produk dan pelayanan konsumen. Setelah melakukan wawancara dengan Pemilik Kedai Kaizar Ibu Gressia Puspa menjelaskan bahwa kini perusahaan masih terus berusaha memberikan pelayanan yang terbaik untuk konsumen. Ibu juga menyadari masih ada banyak kekurangan yang dialami contohnya rasa makanan yang disajikan tidak selalu sama tekadang enak terkadang hambar, penyajian produk antara yang dimenu dengan yang disajikan terkadang berbeda, fasilitas yang ada terbatas bangunan restoran yang tidak terlalu luas, sempitnya lahan parkir terutama untuk roda empat, terbatasnya jumlah karyawan sehingga waktu penyajian makanan sangat lama. Dan juga pelayanan yang minim dikarenakan kekurangan karyawan. Selain itu Kedai Kaizar juga belum pernah melakukan survey terkait kepuasan konsumen. Dan jika restoran ramai, menu yang ditawarkan pada daftar menu tidak semuanya tersedia.

Kedai Kaizar dituntut untuk dapat mengerti apa yang menjadi keinginan atau harapan konsumen dari kualitas produk dan kualitas pelayanan yang diberikan agar tercipta kepuasan bagi konsumennya. Banyaknya kedai kuliner yang tidak dapat mencapai penjualan karena kurangnya evaluasi pada kualitas produk dan pelayanan untuk pemuasan kebutuhan para konsumen, sehingga konsumen sulit untuk dipertahankan.Pada penelitian terdahulu menganalisis pengaruh kualitas pelayanan dan kualitas produk terhadap kepuasan konsumen pada restoran happy garden.

Produk pada Kedai Kaizar yang memuaskan akan memberikan suatu dorongan kepada pelanggan untuk selalu menjalin hubungan yang kuat dengan pihak Kedai Kaizar Lahat tentunya harus dapat meningkatkan kualitas produk dan kepuasan para pelanggannya dengan cara memaksimalkan pengalaman yang menyenangkan mereka dan meminimalkan ataupu menghilangkan pengalaman yang kurang menyenangkan bagi para konsumen. Bila konsumen telah merasa puas dengan apa yang merek dapatkan, tak jarang konsumen akan memberikan informasi kepada rekan dan kerabatnya mengenai apa yang telah mereka dapatkan direstoran tersebut. Secara tidak langsung hal ini akan sangat membantu pihak restoran dalam mempromosikan produknya.

\section{METODE PENELITIAN}

Penelitain ini menggunakan rancangan penelitian Asosiatif Kuantitatif. Menurut Sugiyono (2016: 2) penelitian assosiatif adalah penelitian yang bertujuan mengetahui hubungan dan pengaruh dua variabel atau lebih. Dalam penelitian ini akan dibahas pengaruh kualitas produk dan kualitas pelayanan terhadap kepuasan konsumen di Kedai Kaizar Lahat. 


\section{Populasi dan Sampel}

Populasi yang diambil dalam penelitian adalah seluruh konsumen di Kedai Kaizar Lahat yang berjumlah 150 orang pada bulan Agustus 2020. Jumlah populasi dalam penelitian ini adalah sebanyak 150 orang, sehingga presentase kelonggaran yang digunakan adalah $10 \%(0,10)$ dan hasil perhitungan dapat dibulatkan untuk mencapai kesesuaian. Maka untuk mengetahui sampel penelitian, dengan perhitungan dan didapatkan Sampel penelitian ini adalah konsumen di Kedai Kaizar Lahat yang berjumlah 60 orang.

\section{Definisi Operasional}

Definisi operasional variabel penelitian menurut Sugiyono (2016: 38) adalah suatu atribut atau sifat atau nilai dari obyek atau kegiatan yang memiliki variasi tertentu yang telah ditetapkan oleh peneliti untuk dipelajari dan kemudian ditarik kesimpulannya. Operasional variabel penelitian dalam penelitian yaitu:

a. Kualitas produk (X1), menurut Lupiyoadi (2016: 43)

Adalah salah satu faktor yang paling diandalkan oleh seorang pemasar dalam memasarkan suatu produk.

b. Kualitas pelayanan (X2), menurut Lupiyoadi (2016: 182)

Adalah tingkat keunggulan yang diharapkan dan pengendalian atas tingkat keunggulan tersebut untuk memenuhi keinginan konsumen.

c. Kepuasan konsumen (Y), menurut Sunarto (2015: 11)

Merupakan mengukur sejauh mana harapan konsumen terhadap produk atau jasa yang diberikan dan sesuai dengan aktual produk atau jasa yang ia rasakan.

\section{Teknik Pengumpulan Data}

1. Studi Lapangan (Field Research)

Studi lapangan meruapan suatu metode pengumpulan data untuk mendapatkan data primer dengan cara melakukan pengamatan langsung terhadap objek penelitian, dengan teknik pengumpulan data, yaitu observasi, wawancara, dan kuisoner.

2. Studi Pustaka (Liblary Research)

Studi Pustaka merupakan penelitian yang dilakukan dengan membaca literature yang relevan dengan permasalahan yang diteliti untuk mendapatkan landasan teori. 


\section{Teknik Analisis Data}

\section{Analisis Deskriptif}

Analisis deskriptif yaitu analisis yang ditunjukkan pada perkembangan dan pertumbuhan dari suatu keadaan dan hanya memberikan gambaran tentang keadaan tertentu dengan cara menguraikan tentang sifat-sifat dari obyek penelitian tersebut (Danang, 2017: 74). Analisis ini menggunakan bantuan program SPSS versi 20.0, dengan tabel Descriptive Statistics. Analisis deskriptif memberikan gambaran suatu data yang dilihat dari kiasaran teoritis, kisaran sesungguhnya, rata-rata hitung (mean) dan standar deviasi (standard deviation).

\section{Uji Kualitas Data}

\section{- Uji validitas}

Uji validitas menurut Danang (2017: 85) adalah pengujian untuk mengukur sah atau valid tidaknya suatu kuisioner. Alat untuk mengukur validitas adalah korelasi product moment dari pearson yang di proses dengan SPSS versi 20.0. Secara statistik, angka korelasi yang diperoleh harus dibandingkan dengan angka kritik nilai r.

\section{- Uji Reliabilitas}

Uji reliabilitas menurut Danang (2017: 81) adalah alat untuk mengukur suatu kuisioner yang merupakan indikator dari variabel atau konstruk. Alat untuk mengukur reliabiltas adalah cronbach's alpha yang di proses dengan SPSS versi 20.0.

\section{* Uji Asumsi Klasik \\ * Uji Normalitas Data}

Uji normalitas bertujuan untuk menguji apakah dalam model regresi variabel pengganggu atau residual mempunyai distribusi normal (Danang, 2017: 92). Data yang akan dianalisis dengan regresi linear harus mempunyai distribusi yang normal. Uji Normalitas kali ini menggunakan metode dari Kolmogorov-Smirnov, dengan menggunakan aplikasi SPSS versi 20.0.

Pengujian ini dilakukan dengan melihat penyebaran data pada sumbu diagonal dari grafik atau dengan melihat histogram dari residualnya.

\section{- Uji Multikolinearitas}

Uji multikolinearitas merupakan hubungan linier yang sempurna antara beberapa atau semua variabel bebas (Danang, 2017: 87). Dalam model regresi yang baik seharusnya tidak terjadi korelasi diantara variabel bebas (Ghozali, 2018: 62). Ada tidaknya multikolinearitas dapat dideteksi dengan menggunakan SPSS versi 20.0. 


\section{- Uji Heteroskedastisitas}

Uji heteroskedastisitas bertujuan menguji apakah dalam model regresi terjadi ketidaksamaan variance dari residual satu pengamatan ke pengamatan yang lain (Danang, 2017: 90). Pengujian ini menggunakan bantuan program SPSS versi 20.0.

\section{Analisis Regresi Linier Ganda}

Analisis regresi linier berganda menurut Danang (2017: 47) merupakan analisis yang digunakan untuk mengetahui besarnya pengaruh variabel independen terhadap variabel dependen. Pada penelitian ini menggunakan alat bantu program statistic SPSS versi 20.0 untuk mempermudah proses pengolahan data-data penelitian dari program tersebut akan didapatkan output berupa hasil pengolahan dari data yang telah dikumpulkan, kemudian diinterprestasikan akan dilakukan analisis terhadapnya.

\section{Analisis Koefesien Korelasi}

Analisis koefesien korelasi berganda digunakan untuk melihat kuat lemahnya hubungan antara yariabel bebas dan terikat (Danang, 2017: 57). Nilai korelasi berkisar dalam rentang 0 sampai 1 atau 0 sampai -1. Tanda positif menunjukkan arah perubahan yang sama. a. Tanda negatif menunjukkan arah perubahan yang berlawanan.

\section{Analisis Koefisien Determinasi}

Analisis Koefisien Determinasi menurut Danang (2017: 60) digunakan untuk mengetahui seberapa besar pengaruh variabel bebas terhadap variabel terikat. Nilai r Square atau Koefisien Determinasi $\left(\mathrm{r}^{2}\right)$ dapat dilihat pada hasil pengolahan data bagian model summary yang di proses dengan SPSS versi 20.0.

\section{Pengujian hipotesis secara parsial (Uji-t)}

Uji hipotesis secara parsial menurut Sugiyono (2016: 138) digunakan untuk mengetahui pengaruh dari masing-masing variabel bebas (kepuasan konsumen) terhadap variabel terikat (kualitas produk dan kualitas pelayanan). Uji ini dilakukan dengan membandingkan nilai thitung dengan nilai ttabel. Nilai thitung dapat dilihat dari hasil pengolahan data bagian Coefficients program SPSS versi 20.0. 


\section{Pengujian hipotesis secara simultan (Uji F)}

Uji F menurut Sugiyono (2016: 192) digunakan untuk menguji tingkat signifikan dari pengaruh variabel bebas secara serempak terhadap variabel terikat. Nilai Fhitung dapat dilihat dari hasil pengolahan data bagian ANOVA program SPSS versi 23.0.

\section{HASIL DAN PEMBAHASAN}

\section{Deskripsi Objek Penelitian}

Kedai Kaizar Lahat adalah sebuah rumah makan yang didirikan oleh Ibu Grasia Puspa Juanda yang sudah berdiri \pm 3 tahun lamanya. Kedai Kaizar Lahat memiliki menu masakan rumahan yang mengingatkan kita pada masakan ibu, Kedai Kaizar Lahat tidak hanya menjual masakan rumahan saja seiring jalan dengan kemajuan teknologi yang canggih saat ini kedai kaizar juga memberanikan diri untuk membuat makanan ringan, hal ini dilakukan oleh pemilik Kedai Kaizar Lahat agar kedai dapat menarik perhatian konsumen yang pada saat ini sangat menyukai makanan yang berbau masakan luar negeri.

Dengan mengikuti tren masakan masa kini Kedai Kaizar Lahat dapat bersaing dengan kedai lainnya. Visi dari Kedai Kaizar Lahat adalah "Menjadi rumah makan yang maju, kompetitif dan memiliki cita rasa yang tinggi dan berkualitas”. Dengan misi sebagai berikut:

1) Menjadikan kedai yang mengedepankan kualitas produk.

2) Menjadi kedai yang selalu kreatif dan inovatif.

Sedangkan tujuan Kedai Kaizar Lahat antara lain:

1) Membangun usaha dengan berkomitmen konsumen satisfaction.

2) Mengembangkan usaha dan membuka lapangan pekerjaan untuk masyarakat.

Berbagai macam hidangan makanan Kedai Kaizar Lahat, antara lain: nasi tumpeng ulang tahun dan paket nasi samin, nasi kebuli, pindang salai, terong hehancang, pindang tulang. Menu lain yang tak kalah menggoda adalah ayam goreng kampung masak nanas, Pindang patin dan aneka sayuran seperti cah kangkung, karedok, sayur asem, cap cay. Beberapa pilihan sambal dan minuman segar yang menjadi pelengkap hidangan, serta makanan ringan seperti kue sus, donat, pai dan masakan kekinian lainnya. 
Pembagian tugas dapat dirinci masing-masing bagian dalam perusahaan sebagai yang dirinci pada Tabel 1 berikut.

Tabel 1. Rincian Tugas Kedai Kaizar Lahat

\begin{tabular}{|c|c|}
\hline Bagian & Tugas \\
\hline Pemilik & $\begin{array}{l}\text { - Memutuskan dan menentukan peraturan dan kebijakan } \\
\text { tertinggi } \\
\text { - Merencanakan serta mengembangkan sumber-sumber } \\
\text { pendapatan dan pembelanjaan kekayaan kedai. } \\
\text { - Meningkatkan sistem operasional, proses dan kebijakan dalam } \\
\text { mendukung kedai. } \\
\text { - Membuat pengembangan operasi dalam jangka pendek dan } \\
\text { jangka panjang } \\
\text { - Mengelola dan meningkatkan efektivitas dan efesiensi } \\
\text { operasional kedai. }\end{array}$ \\
\hline Koki & $\begin{array}{l}\text { - Menjaga kualitas rasa makan serta food cost standart (standar } \\
\text { harga) } \\
\text { - Mengawasi sepenuhnya tempat penyimpanan makanan dan } \\
\text { peralatan-peralatan yang akan digunakan. }\end{array}$ \\
\hline $\begin{array}{l}\text { Pelayan/ } \\
\text { Pramusaji }\end{array}$ & $\begin{array}{l}\text { - } \quad \text { Menyajikan makanan dan minuman } \\
\text { - } \quad \text { Berpakaian rapi dan bersih dengan memakai nama tag. }\end{array}$ \\
\hline Kasir/ Keuangan & $\begin{array}{l}\text { - Merencanakan dan mengatur pembiayaan kedai } \\
\text { - } \quad \text { Mengontrol keluar masuknya keuangan kedai. }\end{array}$ \\
\hline Pemasaran & $\begin{array}{l}\text { - Merencanakan dan merumuskan kebijakan strategi dalam } \\
\text { pemasaran. } \\
\text { Mengidentifikasikan kebutuhan konsumen dan tingkat } \\
\text { persaingan sehingga dapat ditentukan rencana volume } \\
\text { (jumlah) penjualan }\end{array}$ \\
\hline Umum & $\begin{array}{l}\text { Bertugas untuk membantu pekerjaan yang ada di kedai ini, agar } \\
\text { bisa terlaksana semua dengan baik dan jika ada kekurangan } \\
\text { dibagian lainya bisa untuk melengkapi. }\end{array}$ \\
\hline
\end{tabular}

Tabel 2. Descriptive Statistics

\begin{tabular}{|c|c|c|c|c|c|}
\hline & $\mathbf{N}$ & Minimun & Maximum & Mean & Std. Deviation \\
\hline Kualitas Produk & 60 & 32.00 & 49.00 & 41.3500 & 4.97051 \\
\hline Kualitas Pelayanan & 60 & 32.00 & 47.00 & 42.0000 & 4.34527 \\
\hline Kepuasan Konsumen & 60 & 30.00 & 50.00 & 41.6333 & 4.69391 \\
\hline Valid N (listwise) & 60 & & & & \\
\hline
\end{tabular}

Tabel 1 maka dapat dideskripsikan nilai-nilai variabel kualitas produk memiliki nilai terendah (minimum) sebesar 32,00 dan nilai tertinggi (maximum) sebesar 49,00 dengan nilai rataratanya sebesar 41,3500 dan standar deviasinya (tingkat sebaran datanya) sebesar 4,97051, sehingga standar deviasi lebih kecil dari nilai rata-rata. Variabel kualitas pelayanan memiliki nilai terendah (minimum) sebesar 32,00 dan nilai tertinggi (maximum) sebesar 47,00 dengan nilai rata-ratanya 
sebesar 42,0000 dan standar deviasinya (tingkat sebaran datanya) sebesar 4,34527, sehingga standar deviasi lebih kecil dari nilai rata-rata. Sedangkan variabel kepuasan konsumen memiliki nilai terendah (minimum) sebesar 30,00 dan nilai tertinggi (maximum) sebesar 50,00 dengan nilai rataratanya sebesar 4, 6333 dan deviasinya (tingkat sebaran datanya) sebesar 4,69391 sehingga standar deviasi lebih kecil dari nilai rata-rata.

\section{KESIMPULAN}

Hasil analisis data dan pengujian hipotesis yang telah diuraikan, maka dapat diambil kesimpulan bahwa variabel kualitas produk $\left(X_{1}\right)$ dan variabel kualitas pelayanan $\left(X_{2}\right)$ bernilai 0 (nol), maka nilai variabel kepuasan konsumen (Y) akan berada pada angka 0,933. Koefisien regresi $X_{1}$ (variabel kualitas produk) dari perhitungan nilai berganda didapat nilai coefficients sebesar 0,562. Koefisien regresi $X_{2}$ (variabel kualitas pelayanan) dari perhitungan nilai berganda didapat nilai coefficients sebesar 0,460. Hasil analisis keoefesien korelasi berganda (r) sebesar 0,856 menunjukkan bahwa keeratan pengaruh langsung antara variabel kualitas produk dan variabel kualitas pelayanan dengan kepuasan konsumen Kedai Kaizar Lahat adalah 85,6 \%, memiliki hubungan ini secara statistik tergolong kuat. Besarnya nilai koefesien determinasi $\left(r^{2}\right)$ berdasarkan tabel pengolahan data SPPS sebesar 0,723. Nilai t hitung dapat dilihat pada hasil pengolahan data SPSS dengan tingkat signifikan $5 \%$ dan degrees of freedom (df) dengan dk penyebut 60, maka $\mathrm{t}$ tabel adalah 2,000.

Nilai $\mathrm{t}$ hitung dapat dibandingkan dengan $\mathrm{t}$ tabel dan perihal tersebut dapat menjadi penarikan kesimpulan juga di tiap variabel, terutama variabel kualitas produk dengan $\mathrm{t}$ hitung > dari t tabel atau 8,000 > 2,000, maka $H_{0}$ ditolak, $H_{a}$ diterima, hal ini menunjukan bahwa terdapat pegaruh yang signifikan antara kualitas produk terhadap kepuasan konsumen Kedai Kaizar Lahat. Sedangkan, variabel kualitas pelayanan dengan t hitung > dari t tabel atau 5,733>2,000, maka $H_{0}$ ditolak, $H_{a}$ diterima, hal ini menunjukan bahwa terdapat pegaruh yang signifikan antara kualitas pelayanan terhadap kepuasan konsumen Kedai Kaizar Lahat.

Pengolahan data SPSS nilai $\mathrm{F}$ tabel dengan tingkat signifikan $5 \%$ dan degrees of freedom (df) dengan dk penyebut 60 adalah sebesar 2,76. Dari hasi uji hipotesis pada penelitian maka keputusan yang diambil adalah $H_{0}$ ditolak, $H_{a}$ diterima, artinya secara bersama-sama variabel kualitas produk dan variabel kualitas pelayanan secara keseluruhan mempunyai pengaruh yang signifikan terhadap variabel kepuasan konsumen Kedai Kaizar Lahat. 


\section{DAFTAR PUSTAKA}

Arief, Muhtosim. 2016. Pemasaran Jasa dan Kualitas Pelayanan. Bayumedia Publishing, Malang. Assauri, Sofjan. 2016. “Manajemen Bisnis dan Pemasaran”. PT. Raja Grafindo Persada, Jakarta.

Eka Prata. 2015. Jurnal, Pengaruh Kualitas Pelayanan dan Kualitas Produk terhadap Kepuasan Konsumen pada restoran Happy Garden. Universitas Kristen Petra, Surabaya.

Ghozali, Imam. 2016. Aplikasi Analisi Multivariate dengan Program IBM SPSS 19 Edisi 5". Semarang: Badan Penerbit Universitas Diponegoro Semarang..

Gudono. 2015. Teori Organisasi. Pensil Press, Sleman.

Kotler, Philip. 2015. Manajemen Pemasaran, Edisi Bahasa Indonesia. PT. Prehalindo, Jakarta.

Kotler, Philip \& Armstrong, 2016. Prinsip-prinsip Pemasaran. Penerbit Erlangga, Jakarta.

Kotler dan Keller. 2015. Manajemen Pemasaran, Edisi Bahasa Indonesia. Erlangga, Jakarta.

Lupiyoadi. 2016. Manajemen Pemasaran Jasa. Salemba Empat, Jakarta.

Sunarto. 2015. Perilaku Konsumen. Yogyakarta : AMUS Jogyakarta dan CV Ngeksigondo Utama.

Sugiyono. "Metode Penelitian Kuantitatif dan Kualitatif dan R \& D”. Alpabeta, Bandung, 2016.

Sunyoto, Danang. 2016. “Metodelogi Penelitian Akutansi”. PT. Rafika Aditama, Jakarta. 